\title{
Histologia e ultra-estrutura do vaso dorsal de Scaptotrigona postica (Hymenoptera, Apidae) em operárias e rainhas de diferentes idades
}

\author{
Silvana B. Poiani \& Carminda da Cruz-Landim ${ }^{1}$
}

1. Departamento de Biologia, Instituto de Biociências de Rio Claro, UNESP, Caixa Postal 199, Av. 24A, 1515, Bela Vista, 13506-900 Rio Claro, São Paulo, Brasil. (cclandim@rc.unesp.br)

\begin{abstract}
Histology and ultrastructure of the dorsal vessel of Scaptotrigona postica (Hymenoptera, Apidae) in workers and queens of various ages. The dorsal vessel is a tubular organ located in the mid-dorsal region of the insects body, just below the tegument. This work is a light and electron microscopy study of the abdominal part of the vessel, the heart, in a stingless bee species. Workers and queens of several ages were studied. The heart is located inside the pericardial sinus. Its wall presents openings or ostia provided with valves and is composed by special striated muscular fibers. The cardiac fiber presents myofibrils irregularly arranged, round or elongated nuclei, numerous and large mitochondria, and glycogen deposits. Old workers and queens present fibers degeneration, represented by autophagic vacuoles, mitochondria alterations and accumulation of myelinic bodies. In conclusion, the heart of Scaptotrigona postica Latreille, 1807 is similar to other insects. The changes found are related to aging progress and maintain temporal relationship with the caste life expectancy.
\end{abstract}

KEYWORDS. Bee, cardiac muscle, celular changes, senescence.

RESUMO. O vaso dorsal é um órgão tubular localizado na região mediano-dorsal do corpo dos insetos, abaixo do tegumento. Fez-se um estudo de microscopia de luz e eletrônica de transmissão da porção abdominal do vaso dorsal, o coração, em uma espécie de abelha indígena. Foram estudadas operárias e rainhas em diferentes idades. O coração está localizado no sinus pericárdico. A parede cardíaca é formada por fibras musculares estriadas e apresenta aberturas ou ostíolos providos de válvulas. A fibra cardíaca contém miofibrilas arranjadas irregularmente, núcleos alongados ou redondos, mitocôndrias grandes e numerosas, e depósitos de glicogênio. Em operárias e rainhas longevas, as fibras encontram-se em degeneração, evidenciada por vacúolos autofágicos, alterações mitocondriais e acúmulo de corpos mielínicos. Em conclusão, o coração de Scaptotrigona postica é semelhante ao de outros insetos estudados. As alterações encontradas estão relacionadas ao processo de envelhecimento e mantêm relação temporal com a expectativa de vida da casta.

PALAVRAS-CHAVE. Abelha, músculo cardíaco, alterações celulares, envelhecimento.

O sistema circulatório dos insetos é do tipo aberto, com o sangue circulando principalmente pela atividade de contração de um vaso longitudinal mediano-dorsal, localizado no sinus pericárdico, limitado pelo tegumento e pelo diafragma dorsal. Este vaso diminui de diâmetro à medida que se direciona da região posterior para a anterior, recebendo a denominação de coração no abdômen, onde é muscular e pulsátil, e de aorta no tórax (CHAPMAN, 1998).

A histologia e a ultra-estrutura do vaso dorsal já foram estudadas em insetos de diferentes ordens, merecendo menção os trabalhos com Hymenoptera: Apis mellifera Linnaeus, 1758 (CRUZ-LANDIM, 1974) e Scaptotrigona postica Latreille, 1807 (CRUZ-LANDIM \& MeLo, 1981); Orthoptera: Locusta migratoria Linnaeus, 1758 (HoffMANn \& Lévi, 1965); Diptera: Drosophila repleta Wollaston, 1858 (Sohal, 1970; Burch et al., 1970), Musca domestica Linnaeus, 1758 (SoHAl \& Allison, 1971), Drosophila melanogaster Meigen, 1830 (CuRTIs et al., 1999) e Protophornia terraenovae Robineau-Desvoidy, 1830 (ANGIOY et al., 1999); e Heteroptera: algumas famílias relacionadas e analisadas por HiNKs (1966).

De modo geral, o coração é formado por células musculares estriadas, dispostas helicoidal- ou circularmente (SNODGRASS, 1956) e, segundo CRUZ-LANDIM (1981), em abelhas, uma única célula perfaz o perímetro do vaso dorsal. Ultra-estruturalmente, a fibra cardíaca apresenta-se ocupada principalmente por miofibrilas arranjadas irregularmente e mitocôndrias de forma e tamanho variados (CRUZ-LANDIM, 1974).

A maioria dos estudos realizados com o vaso dorsal dos insetos é de caráter descritivo e qualitativo. Porém, alguns trabalhos abordam mecanismos fisiológicos como, por exemplo, a função secretora das fibras (LOCKE, 1989), a atividade elétrica no desenvolvimento da musculatura cardíaca (McCANN, 1970) e o envelhecimento desta (Burch et al., 1970; Sohal, 1970; Sohal \& Allison, 1971).

Cruz-Landim \& Melo (1981) descreveram o vaso dorsal de Scaptotrigona postica, mas limitaram-se à casta operária e à microscopia de luz. Com a finalidade de aprofundar o estudo do vaso dorsal nesta espécie, este estudo objetiva descrever a histologia e a ultra-estrutura do coração de operárias e rainhas de Scaptotrigona postica, uma abelha brasileira nativa com ferrão atrofiado, em suas diferentes idades.

\section{MATERIAL E MÉTODOS}

As abelhas utilizadas neste trabalho foram coletadas no meliponário mantido na UNESP de Rio Claro, Estado de São Paulo. O vaso dorsal foi estudado em operárias recém-emergidas, nutridoras e campeiras e rainhas virgens e fecundadas. Capturaram-se 10 indivíduos de cada fase e casta, exercendo funções específicas das etapas da divisão de trabalho, as quais correspondem, de certa maneira, à idade cronológica nas operárias e de reprodução nas rainhas e refletem seu 
desenvolvimento fisiológico. As rainhas virgens capturadas eram recém-emergidas e as fecundadas, rainhas em postura, cuja idade se desconhecia.

Para a análise ao microscópio de luz (ML), o abdômen das abelhas foi retirado e fixado em Bouin aquoso ou paraformaldeído a $4 \%$ em tampão fosfato de sódio, pH 7,4. Em seguida, as peças foram desidratadas em bateria alcoólica com concentração crescente, colocadas em resina de embebição e finalmente incluídas em historesina. Os blocos foram seccionados a $6 \mu \mathrm{m}$ de espessura e os cortes corados com hematoxilina e eosina (HE).

Para a análise ao microscópio eletrônico de transmissão (MET), o coração dos indivíduos foi dissecado, fixado em Karnovisky e pós-fixado em tetróxido de ósmio a $0,5 \%$, contendo ferrocianeto de potássio a $0,8 \%$ dissolvidos em tampão cacodilato de sódio $0,1 \mathrm{M}, \mathrm{pH} 7,4$. Posteriormente à fixação, as peças foram lavadas com o tampão anteriormente mencionado, colocadas em solução aquosa de ácido tânico a $2 \%$ por $3 \mathrm{~h}$ e banhadas em álcool $10 \%$. Em seguida foram deixadas em acetato de uranila a $1 \%$ no escuro durante $2 \mathrm{~h}$, desidratadas em concentrações crescentes de acetona e embebidas com uma mistura de acetona e resina $1: 1$ e depois 1:3. Procedeu-se à inclusão em resina e os blocos foram seccionados com ultramicrótomo. Por último, os cortes ultra-finos foram contrastados com acetato de uranila a $2 \%$ por 45 minutos e citrato de chumbo por 10 minutos, examinados e fotografados em MET.

\section{RESULTADOS}

O sinus pericárdico é limitado pelo tegumento e pelo diafragma dorsal. Além do vaso dorsal, que está localizado na sua região mediano-dorsal, o sinus contém células pericárdicas, do corpo gorduroso e enócitos (Fig. 1). As células pericárdicas podem se agrupar formando cordões. As células do corpo gorduroso são maiores, aparecem em maior número e contêm depósitos lipídicos no citoplasma.

O diafragma dorsal pode ser caracterizado como uma membrana delgada que separa o sinus pericárdico do perivisceral, sobre a qual se estendem os músculos alariformes, prendendo-se às laterais do tegumento, por uma extremidade, e ventralmente à parede do coração, pela outra.

$\mathrm{O}$ vaso dorsal inicia-se em fundo cego na parte posterior do abdômen e diminui de diâmetro da região posterior para anterior. O coração é formado por sucessivas câmaras separadas por estreitamentos que correspondem a aberturas ou ostíolos. As células musculares estriadas que formam a sua parede dispõemse em anéis de modo a limitar o lúmen do vaso. Nos ostíolos, projeções dessas fibras em direção à luz formam válvulas (Fig. 2). A hemolinfa penetra no coração na diástole e é impedida pelas válvulas de sair na sístole. A estrutura da parede do coração nas regiões onde ocorrem as válvulas apresenta-se mais fina que no restante do vaso. $\mathrm{Na}$ aorta, não são encontradas válvulas, nem divisão em câmaras e ostíolos.

Recobrindo externa- e internamente o coração, existe uma lâmina basal espessa, mais espessa internamente, que separa as fibras da hemolinfa (Fig. $3)$. Tanto em operárias quanto em rainhas, o vaso dorsal é formado por fibras musculares estriadas cuja superfície é ondulada. Cada ondulação corresponde ao comprimento de um sarcômero, sendo, portanto, limitada pelas linhas-Z que são bem evidentes, às vezes descontínuas. O sarcoplasma é quase todo preenchido por miofibrilas de arranjo irregular, que muitas vezes se ramificam, além de mitocôndrias. Os núcleos apresentam forma arredondada (Fig. 4) ou alongada e estão localizados central ou perifericamente na fibra cardíaca.

As mitocôndrias formam grupos periféricos ou no centro da fibra, ou ainda, localizam-se em cordões entre as miofibrilas (Figs. 3, 5, 6). Estão presentes grânulos de glicogênio, principalmente ao redor das mitocôndrias.

Em intervalos não muito regulares ocorrem invaginações do sarcolema formando os túbulos do sistema T (Fig. 5). O retículo sarcoplasmático é bem desenvolvido e encontra-se entre as miofibrilas, principalmente ao nível das bandas A e I, onde se associa aos túbulos do sistema $\mathrm{T}$, formando díades. Poucos ribossomos livres são encontrados nas fibras cardíacas. O coração encontra-se bem suprido por traqueídeos.

Não há diferenças anatômicas e ultra-estruturais entre o coração de operárias e de rainhas de Scaptotrigona postica. As diferenças verificadas nas duas castas estabelecem-se com a idade, ocorrendo modificações na ultra-estrutura das fibras musculares. Em operárias recém-emergidas e rainhas tanto virgens como fecundadas, ocorre, em grande quantidade, grânulos de glicogênio (Fig. 6). Nas operárias recémemergidas e nas rainhas virgens, as mitocôndrias podem apresentar forma e tamanho variados e a matriz mitocondrial apresenta densidade eletrônica de média a alta (Fig. 6). As cristas podem se dispor paralelamente ao maior eixo da organela ou de maneira circunferencial. Em operárias nutridoras, as mitocôndrias também apresentam formas variadas. Observou-se predomínio de mitocôndrias com matriz de média densidade eletrônica. Algumas exibem cristas dispostas circunferencialmente.

Já em operárias campeiras e rainhas fecundadas, as mitocôndrias variam no formato, densidade eletrônica, disposição das cristas e predominam tamanhos maiores. É comum as mitocôndrias, principalmente as de baixa densidade da matriz, apresentarem fragmentação das cristas (Figs. 8, 10). Operárias campeiras e rainhas fecundadas, em particular, apresentam alterações degenerativas na fibra cardíaca, evidenciadas por numerosos vacúolos autofágicos com conteúdo de baixa densidade eletrônica contendo granulação fina e estruturas membranosas com arranjo concêntrico em diferentes estágios de formação (Figs. 7, 8). Algumas dessas estruturas apresentam membrana dupla e restos de cristas, indicando que poderiam resultar da degeneração de mitocôndrias. Corpos multivesiculares estão envoltos por uma membrana (Fig. 9). 

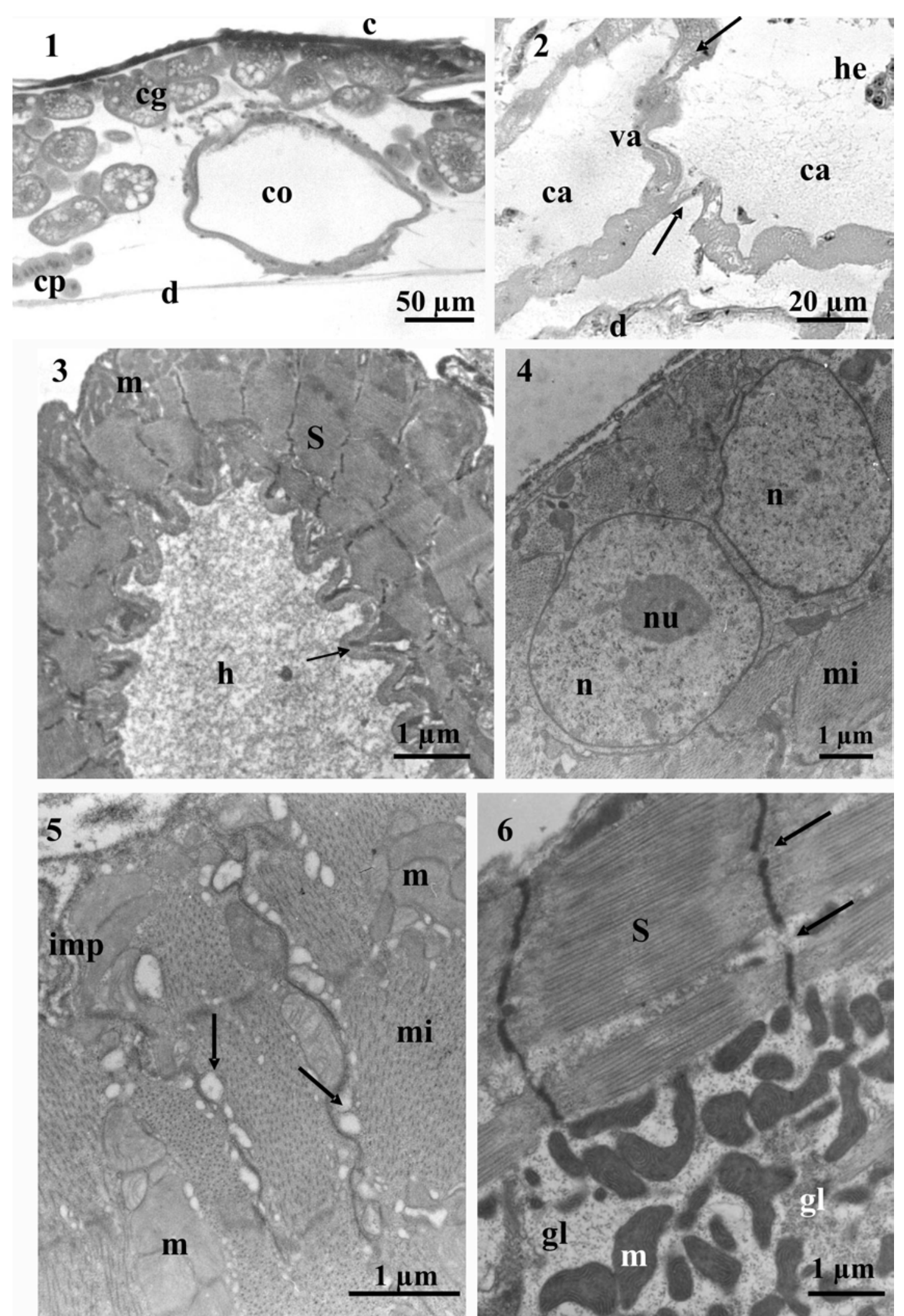

Figs. 1-6. Cortes histológicos e ultra-estruturais do vaso dorsal de Scaptotrigona postica Latreille, 1807: 1, aspecto geral do sinus pericárdico em operária campeira; 2, corte longitudinal do coração em rainha em postura (setas, invaginações da parede cardíaca na região dos ostíolos); 3, corte transversal da ultra-estrutura do músculo cardíaco em operária campeira (seta, lâmina basal); 4, fibra muscular cardíaca de rainha em postura, apresentando dois núcleos centrais arredondados; 5, localização das mitocôndrias e dos túbulos do sistema $\mathrm{T}$ (setas) em operária nutridora; 6, agrupamento de mitocôndrias elétron-densas na fibra cardíaca de rainha virgem (setas, separação entre miofibrilas) (c, cutícula do tegumento; ca, câmara cardíaca; cg, corpo gorduroso; co, coração; $\mathrm{cp}$, células pericárdicas; d, diafragma dorsal; gl, glicogênio; h, hemolinfa; he, hemócitos; imp, invaginação da membrana plasmática; m, mitocôndria; mi, miofibrilas; n, núcleo; nu, nucléolo; S, sarcômero; va, válvula cardíaca). 

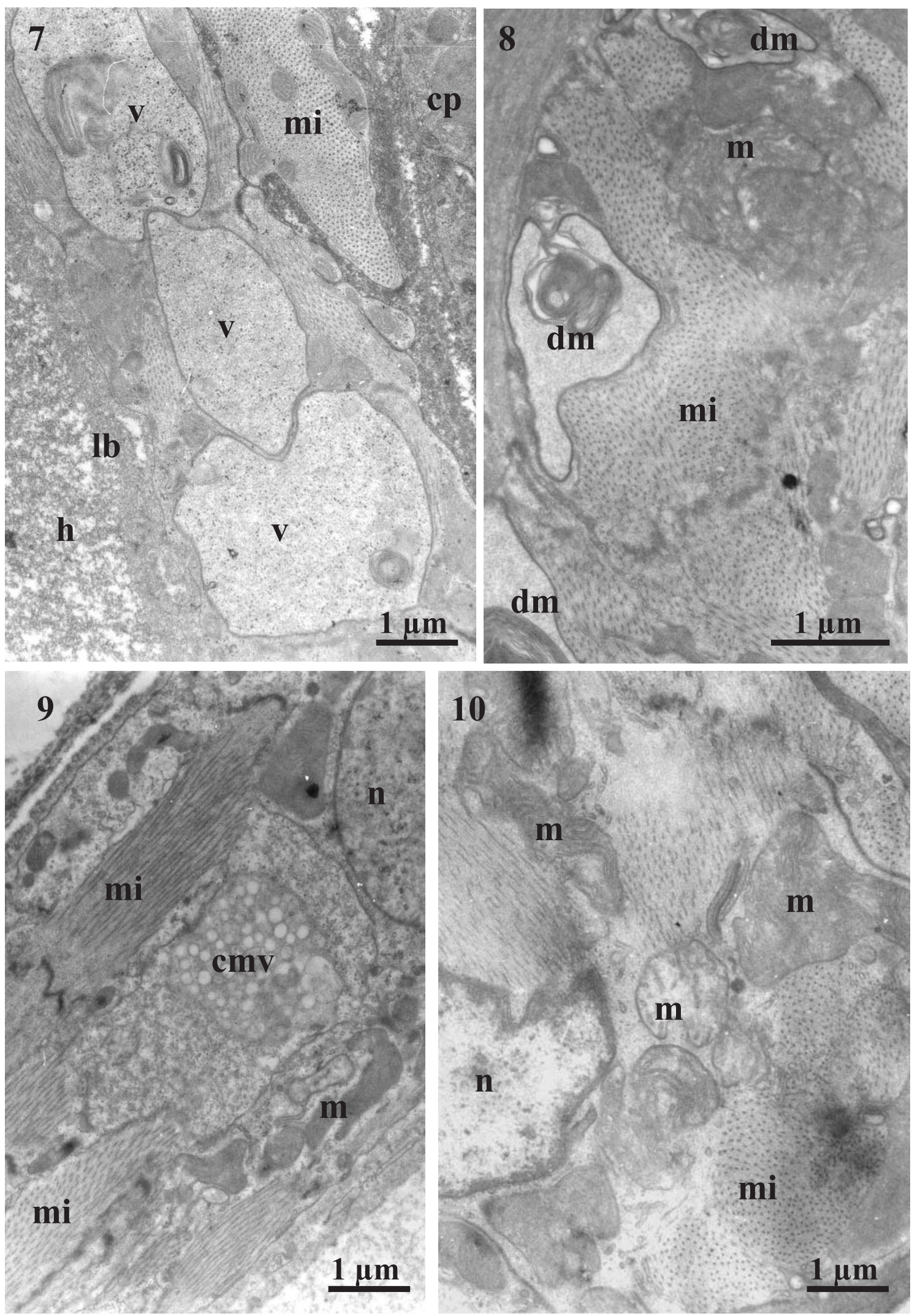

Figs. 7-10. Degeneração muscular no vaso dorsal de Scaptotrigona postica Latreille, 1807: 7, vacúolos contendo granulação fina e estruturas membranosas em operária campeira; 8, degeneração mitocondrial dentro de vacúolo em operária campeira; 9, fibra cardíaca de rainha em postura, mostrando vacúolo contendo vesículas; 10, fragmentação de cristas em mitocôndrias com baixa densidade eletrônica e núcleo irregular em operária campeira (cmv, corpos multivesiculares; cp, célula pericárdica; dm, degeneração mitocondrial; h, hemolinfa; lb, lâmina basal; m, mitocôndria; mi, miofibrilas; n, núcleo; v, vacúolo). 


\section{DISCUSSÃO}

A organização histológica do vaso dorsal de $S$. postica, em operárias e rainhas, é semelhante a dos insetos já pesquisados. A parede cardíaca da espécie estudada é formada por uma única camada de células musculares estriadas como também verificado em hemípteros heterópteros (Hinks, 1966), Lepidoptera (SANGER \& McCANn, 1968), Diptera (Burch et al., 1970; SoHAL, 1970; Sohal \& Allison, 1971; ANGioy et al., 1999; CurTis et al., 1999) e outros Hymenoptera (CRUZ-LANDim, 1974; CruZLandim \& Melo, 1981). Porém, Hoffmann \& Lévi (1965) caracterizaram o vaso dorsal de Locusta migratoria, formado por duas camadas celulares que estão separadas por fibras conjuntivas. Na camada celular externa do vaso, prendem-se células pericárdicas por meio de pedúnculos. Tal situação não foi verificada em $S$. postica.

Os ostíolos na parede cardíaca permitem o fluxo da hemolinfa do sinus pericárdico para o interior do vaso dorsal. A morfologia das válvulas encontradas nas regiões dessas aberturas sugere que estas tenham a função de permitir o fluxo da hemolinfa, impedindo seu refluxo durante a sístole. Portanto, os ostíolos encontrados são do tipo incurrentes. A presença de ostíolos no coração também foi observada em Siphunculata e Mallophaga (HinKs, 1966), P. terraenovae (ANGIOY et al., 1999) e D. melanogaster (CuRTis et al., 1999).

O estudo histológico feito por CRUZ-LANDIM \& MELO (1981) revelou zonas vacuolizadas no coração de operárias campeiras de $S$. postica. No presente estudo, entretanto, não foram evidenciadas vacuolizações à microscopia de luz.

Ultra-estruturalmente, a organização do coração de S. postica mostrou-se similar a de outros insetos. Entre os indivíduos estudados, não foram verificadas mudanças em relação à morfologia geral, porém algumas alterações intracelulares puderam ser observadas quando se tratou das diferentes idades em cada casta. As rainhas fecundadas provavelmente não eram muito jovens, encontrando-se em postura na colônia já há algum tempo, por isso mostravam alterações nas fibras musculares cardíacas semelhantes as das operárias campeiras.

As ondulações na parede cardíaca, correspondentes aos sarcômeros, também foram observadas em $A$. mellifera (CRUZ-Landim, 1974) e $P$. terraenovae (ANGIOY et al., 1999) e podem proporcionar um maior aumento no diâmetro do lúmen durante o relaxamento da musculatura na diástole, possibilitando a entrada de um volume maior de hemolinfa e conferindo um bombeamento mais eficiente da hemolinfa ao longo do vaso dorsal, na sístole.

Não foi observada a presença de junções intercelulares entre as fibras, porém as membranas intercelulares são interdigitadas. Uma lâmina basal espessa externa e internamente ao vaso dorsal, une as fibras musculares em uma única massa funcional. Essa união entre as células facilita a propagação de impulso nervoso, além de separar as fibras cardíacas da hemocele e da hemolinfa. Lâmina basal espessa também foi encontrada em A. mellifera (Cruz-Landim, 1974), $P$. terraenovae (Angioy et al., 1999) e D. melanogaster (CuRTis et al., 1999) recobrindo externa e internamente o coração.
Quanto à disposição das mitocôndrias na fibra muscular, algumas variações ocorrem entre os insetos estudados. Em $S$. postica, a disposição dessas organelas na periferia e no centro da fibra e entre as miofibrilas segue o mesmo padrão observado em A. mellifera (CRUZLANDIM, 1974). Essa disposição indica os locais intracelulares de maior consumo de energia, principalmente entre os sarcômeros. Em Hyalophora cecropia, ocupam a periferia da fibra nas duas superfícies (Hinks, 1966). Em D. repleta (Burch et al., 1970; Sohal, 1970) e M. domestica (Sohal \& Allison, 1971), apenas a superfície oposta ao lúmen e em $P$. terraenovae (ANGIOY et al., 1999) agrupam-se na superfície que limita o lúmen.

Estudo do vaso dorsal em Calpodes (Lepidoptera) e Rhodnius (Hemiptera) mostrou que as células musculares cardíacas secretam proteínas para a hemolinfa. Essas fibras apresentam complexo de Golgi, retículo endoplasmático rugoso e vesículas com material denso (Locke, 1989). No presente estudo, tais estruturas responsáveis pela síntese de proteínas de exportação não foram observadas. Portanto, a musculatura cardíaca de S. postica não possui função secretora.

Nos indivíduos estudados, as linhas-Z dos sarcômeros muitas vezes aparecem como corpos fusiformes descontínuos. Segundo Crossley (1985), os miofilamentos são capazes de passar pelas aberturas nas regiões descontínuas das linhas-Z, resultando em maior força de contração. Outra característica que contribui para uma eficiente e uniforme contração das fibras cardíacas é a presença de invaginações do sarcolema, formando os túbulos do sistema $\mathrm{T}$, os quais constituem díades com o retículo sarcoplasmático (BURCH et al., 1970; SOHAL, 1970; Sohal \& Allison, 1971; Cruz-Landim, 1974; Angioy et al., 1999; CurTis et al., 1999). Estas formações e associações do sarcolema permitem que o estímulo nervoso chegue igualmente até o centro da fibra muscular, resultando em contração mais rápida e uniforme.

Entre os indivíduos estudados, as mitocôndrias variaram em seus aspectos morfológicos e em operárias campeiras predominam organelas maiores. A densidade da matriz em operária recém-emergida e rainha virgem variou de média a alta; em nutridora predominou a densidade média e em campeira e rainha fecundada oscilou de baixa a alta. Portanto, o maior tamanho da organela nas operárias campeiras pode dever-se à sua dilatação por problemas osmóticos, degenerativos. Os vacúolos encontrados em operárias campeiras e rainhas fecundadas representam o estágio final dos processos degenerativos. Já as cristas mitocondriais diferem principalmente em campeiras e rainhas fecundadas, apresentando fragmentação quando a densidade eletrônica da organela é baixa, o que confirma estarem estas mitocôndrias alteradas. Perante o exposto, podese concluir que os indivíduos jovens de cada casta apresentam características mitocondriais semelhantes e o mesmo ocorre entre os indivíduos velhos. Sugere-se que o formato da mitocôndria não interfere na sua capacidade funcional oxidativa. Em indivíduos jovens de D. repleta (Burch et al., 1970; SOHAL, 1970) e M. domestica (SoHAl \& Allison, 1971), as mitocôndrias são ovais e alongadas e a matriz elétron-densa. Cristas irregulares 
foram verificadas apenas em $D$. repleta. Nos espécimes velhos de $D$. repleta, as mitocôndrias são maiores e apresentam acúmulo de glicogênio na matriz e fragmentação das cristas. $\mathrm{O}$ aumento no tamanho mostrou-se independente da quantidade de glicogênio na matriz (Burch et al., 1970; SoHAL, 1970). Indivíduos longevos de M. domestica (Sohal \& Allison, 1971) não apresentaram glicogênio intramitocondrial, mas constataram-se gotículas lipídicas associadas a essas organelas. Em S. postica não foi encontrado glicogênio intramitocondrial, porém foram verificadas gotículas lipídicas na matriz.

A quantidade de glicogênio na fibra cardíaca oscilou entre as idades nas operárias. Operárias recémemergidas e rainhas virgens e fecundadas acumulam mais glicogênio que os demais indivíduos, principalmente na proximidade das mitocôndrias. Talvez esta diferença esteja relacionada com a atividade exercida pela abelha; o forrageio das operárias campeiras exige grande consumo de energia. Portanto, se consomem mais, acumulam menos glicogênio na musculatura. Operárias jovens e rainhas exercem funções dentro da colônia, as quais exigem menos consumo energético se comparado às campeiras, possibilitando, então, maior acúmulo de glicogênio.

Vacúolos autofágicos e corpos multivesiculares só foram observados em operárias campeiras e rainhas fecundadas, ou seja, em indivíduos velhos. A associação com mitocôndrias e a presença de dupla membrana envolvendo o vacúolo sugere que se trate de degeneração mitocondrial. Além disso, as estruturas membranosas tipo figura mielínica presentes entre as miofibrilas, possivelmente são derivadas de autodigestão. A grande quantidade de vacúolos na fibra muscular reflete enfraquecimento na função cardíaca nesses indivíduos. Vacúolos autofágicos, figuras mielínicas, degeneração nuclear e corpos densos estão presentes na musculatura cardíaca de indivíduos velhos de D. repleta (BuRCH et al., 1970; SoHAL, 1970).

Em conclusão, demonstrou-se não haver diferenças na organização do músculo cardíaco entre operárias e rainhas, apesar das funções diferentes que desempenham na colônia. Por outro lado, também comprovou-se que o processo de envelhecimento da musculatura ocorre de maneira semelhante em ambas castas.
Agradecimentos. Os autores agradecem o financiamento do CNPq (Processo 520566/95-5) e da FAPESP (Processo 03/ 05697-8).

\section{REFERÊNCIAS BIBLIOGRÁFICAS}

Angioy, A. M.; Bonssa, D. \& Dulcis, D. 1999. Functional morphology of the dorsal vessel in the adult fly Protophornia terraenovae (Diptera, Calliphoridae). Journal of Morphology 240:15-31.

Burch, G. E.; Sohal, R. \& Fairbanks, L. D. 1970. Ultrastructural changes in Drosophila heart with age. Archives of Pathology, 89: $128-136$.

Chapman, R. F. 1998. The Insects: structure and function. 4 ed. London, English Press. 420p.

Crossley, A. C. 1985. The morphology and development of the Drosophila muscular system. In: Ashburner, M. \& Wright, T. R. F. orgs. The genetics and biology of Drosophila. London, Academic. v.2., p.499-560

Cruz-Landim, C. 1974. Aspectos ultra-estruturais do músculo cardíaco de Apis mellifera L. (Hymenoptera, Apidae). Revista Brasileira de Biologia 34(1):105-113.

1981. Ultra-estrutura das células pericárdicas de Apis mellifera L. (Hymenoptera: Apidae). Naturalia 6:63-74.

Cruz-Landim, C. \& Melo, R. A. 1981. Desenvolvimento e envelhecimento de larvas e adultos de Scaptotrigona postica Latreille (Hymenoptera: Apidae): aspectos histológicos e histoquímicos. São Paulo, ACIESP. n.31, 118 p.

Curtis, N. J., Ringo, J. M. \& Dowse, H. B. 1999. Morphology of the pupal heart, adult heart and associate tissues in the fruit fly, Drosophila melanogaster. Journal of Morphology 240 (3):225-235.

Hinks, C. F. 1966. The dorsal vessel and associated structures in some Heteroptera. Transactions of the Royal Entomological Society of London 118(12):375-392.

Hoffmann, J. A. \& LÉvi, C. 1965. Étude au microscope eletronique du vassau dorsal de Locusta migratoria. Comptes Rendus des Séances de L'Académie des Sciences 260(26):69886990.

Locke, M. 1989. Secretion by insect heart muscle cells. Journal of Insect Physiology 35(1):53-56.

McCann, F. V. 1970. Physiology of insect heart. Annual Review of Entomology (15):173-200.

SANGer, J. W. \& McCANn, F. V. 1968. Ultrastructure of the myocardium of the Hyalophora cecropia. Journal of Insect Physiology 14:1105-1111.

Snodgrass, R. E. 1956. Anatomy of the honey bee. New York, Vail-Ballow. 334p.

Sohal, R. S. 1970. Mitochondrial changes in the heart of Drosophila repleta, Wollaston with age. Experimentia Gerontology 5:213-216.

Sohal, R. S. \& Allison, V. F. 1971. Senescent changes in the cardiac myofiber of the house fly, Musca domestica. An electron microscopic study. Journal of Gerontology 26(4):490-495. 